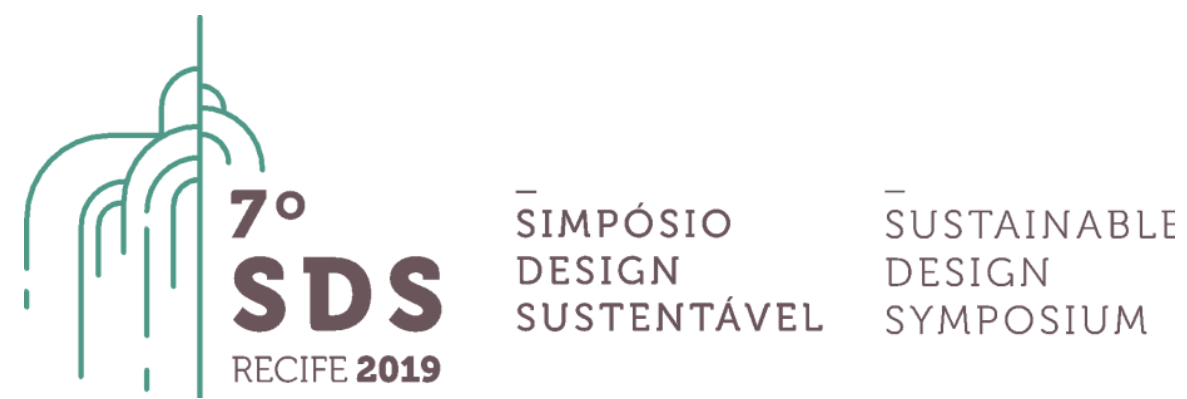

\title{
ANÁLISE DO DIFERENCIAL DE UMA LINHA ECOLÓGICA DE PRODUTOS PARA UTILIDADES DOMÉSTICAS
}

\author{
Luiza Grazziotin Selau', Sabrina Parenza ${ }^{2}$ e Daiane de Gasperi ${ }^{3}$ \\ ${ }^{1}$ FSG Centro Universitário, Design, luizagselau@gmail.com \\ ${ }^{2}$ FSG Centro Universitário, Design, sabrinaparenza@hotmail.com \\ ${ }^{3}$ FSG Centro Universitário, Design, daidegasperi@daidegasperi.com.br
}

\begin{abstract}
Resumo. $O$ presente artigo tem como objetivo verificar o diferencial de sustentabilidade proposto por uma linha de produtos denominada Ecológica, de uma empresa de utilidades domésticas em plásticos, situada em Caxias do Sul RS. Tal análise visa ressaltar a importância do design sustentável e a necessidade do envolvimento do designer em todo o processo de desenvolvimento de produtos. Utilizou-se de questionário para analisar quais os pontos no ciclo de vida dos produtos da linha Ecológica são realmente diferentes dos produtos das outras linhas da mesma empresa, e qual o grau de sustentabilidade que esta linha carrega em seus produtos além do nome. Percebeu-se que mesmo com alguns procedimentos de produção que diferenciam a linha das outras, muito mais poderia ser feito para que ela de fato fosse ecológica, porém é possível compreender que nem sempre é simples para a empresa alterar todo seu processo produtivo. Desta forma, conclui-se que a empresa realiza o que está ao seu alcance para que a linha se destaque e tenha menor impacto e maior coerência com sua divulgação e diferencial ecológico.
\end{abstract}

Palavras-chave. Design, Sustentabilidade, Ecodesign, Ciclo de vida.

\section{Introdução}

A sustentabilidade tem sido cada vez mais discutida tendo em vista a conscientização acerca dos problemas ambientais decorrentes do sistema de produção e consumo vigentes. Não era um assunto em pauta no século passado, onde o crescimento descontrolado e o desenvolvimento global aconteciam de forma acelerada e os recursos naturais não renováveis estavam disponíveis em abundância no planeta, ou seja, não era motivo de preocupação no meio de tantas mudanças no contexto e estilo de vida em geral.

Passado um século o tema ganha força, pois o desenvolvimento econômico, social e industrial, o diferente modo de habitar o planeta e as drásticas mudanças ambientais geradas pela falta de conscientização, dependem basicamente de como esses recursos finitos são utilizados, e quando se percebe que os mesmo estão ficando escassos ocorre uma desesperada busca pela resolução deste problema. 
Quanto maior o consumo e a produção de produtos, mais o meio ambiente é prejudicado devido ao aumento da necessidade de recursos para a fabricação, resultando na posterior geração de lixo. Cardoso (2008) argumenta que o dilema do designer no contexto atual é conciliar as questões ambientais com o modelo econômico. O designer é responsável pelos produtos que a população encontra a venda, e deve utilizar ferramentas de projeto que atendam aos requisitos da sustentabilidade e agreguem valor ecológico aos produtos desenvolvidos.

Por isso existem empresas preocupadas em apresentar produtos que tenham este valor agregado, pondo em destaque esta preocupação ambiental que rondou o produto em sua produção ou qualquer requisito sustentável utilizado como diferencial, para que haja a possibilidade de destaque no comércio devido a estas questões.

Nesse panorama, Vezzoli (2010) argumenta que o design é uma parte do problema, mas, no entanto, pode vir a se tornar um agente promotor da sustentabilidade ao buscar novas alternativas de projeto. Um dos pontos positivos da atuação do designer salientada por Lawson (2006) é a de que as situações de design variam não só por conta de desafios diferentes, mas também por adotar abordagens distintas. Sendo assim a abordagem de eco design apresenta-se como uma ferramenta valiosa, uma vez que busca minimizar os impactos ambientais ao longo de todo o ciclo de vida do produto, desde sua concepção até seu descarte.

Este artigo faz parte de uma análise de um possível diferencial em uma linha de produtos denominada Ecológica de uma empresa de utilidades domésticas em plásticos situada em Caxias do Sul - RS. A partir de referencial teórico, entrevista e coleta de dados, pretende-se verificar se o produto pode ser denominado "ecologicamente correto", no que diz respeito a minimizar os impactos ambientais e ser uma alternativa de consumo consciente.

O trabalho está estruturado da seguinte forma: Introdução que ressalta a origem da pesquisa e a relevância do tema; Referencial teórico onde são elucidados alguns conceitos que darão sustentação as ideias defendidas no artigo; Metodologia etapa que descreve o processo de coleta de dados e o tipo de investigação utilizada; Análise e discussão onde são apresentados os dados, e os mesmo são comparados aos itens pesquisados, aos resultados e referenciais teóricos; e por fim, Considerações finais que se referem ao fechamento da proposta, aspectos positivos e negativos e expectativas futuras.

\section{DESENVOLVIMENTO}

Nesta etapa serão apresentadas visões de autores considerados referencias em cada assunto, abordando primeiramente a relação de design e sustentabilidade, após a explicação sobre a abordagem de ecodesign e por fim a apresentação da empresa escolhida para a análise.

\subsection{Design e Sustentabilidade}

O panorama atual do sistema de desenvolvimento de produtos exige uma atividade de projetar a partir de requisitos ambientais que devem ser considerados e abordados no projeto dos mesmos. A questão da sustentabilidade teve suas primeiras manifestações no âmbito de contrariedade à contaminação do meio ambiente nos anos 60, a partir dos anos 90 o debate do tema passou a ser apresentado de forma mais madura e consistente, e foi quando também o design se inseriu no desafio devido ao "seu papel de protagonista dentro da trilogia: ambiente, produção e consumo" (DE MORAES, 2010, p. 60). Fazendo relação à atividade do designer, percebe-se com estes três termos - ambiente, produção e consumo - a necessidade do equilíbrio entre o ambiental, o econômico e o social, que formam o já difundido conceito de 'três pilares da sustentabilidade'.

Os países desenvolvidos passaram a colocar a ênfase da sustentabilidade na questão ambiental, assim percebe-se a preocupação de países em desenvolvimento em incluir também a 
questão socioeconômica. Fica clara a oposição e fatídica relação de questões como o esgotamento dos recursos naturais e aumento crescente de resíduos do pós-consumo. Visando a interferência nesta lógica atual é possível afirmar que o papel do designer "pode ser sintetizado como a atividade que, ligando o tecnicamente possível com o ecologicamente necessário, faz nascer novas propostas que sejam social e culturalmente apreciáveis" (MANZINI E VEZZOLI, 2008, p. 20).

A importância de estudar as questões da sustentabilidade atualmente, se deve ao fato de que é clara a situação devastada que o planeta se encontra. É preciso que as pessoas compreendam as condições atuais, e percebam que estas são consequências das atitudes da geração passada, a qual não tinha conhecimento das possíveis implicações de suas ações. Como enfatiza De Moraes (2010, p. 59) "a escassez de recursos naturais, a previsão do impacto ambiental, o controle do consumo de bens não renováveis e o descarte consciente não fizeram parte das disciplinas que constituíram a solidez moderna".

A orientação da inovação rumo à sustentabilidade para os designers é a capacidade de dar uma orientação estratégica às próprias atividades, na sua habilidade em definir objetivos que combinem suas próprias necessidades e exigências com os critérios de sustentabilidade que estão gradualmente vindo à tona. Organizá-las num sistema coerente de produtos e serviços regenerativos, comunicar tais visões e sistemas adequadamente para que sejam reconhecidos e avaliados por um público suficientemente amplo, capaz de aplicá-las efetivamente. (MANZINI, 2008). Margolin (2004), afirma que os designers devem trabalhar de forma social e que se não faz sentido imaginarmos um mundo sem produtos, falta então uma teoria de ação social na concepção dos mesmos para que se possa explicar a sua relação com a atitude humana reforçando e auxiliando o trabalho dos designers sociais.

\subsection{Abordagem de ecodesign}

Manzini e Vezzoli (2008) afirmam que é possível conceber produtos mais sustentáveis, utilizando-se tecnologias limpas, reduzindo-se recursos e energia utilizados na produção, dentre alternativas que se caracterizam como novo campo de pesquisa do design. Algumas estratégias são utilizadas para unir design e sustentabilidade, por exemplo, através da implantação da análise do ciclo de vida dos produtos (Life Cycle Design - LCD) e de outras estratégias projetuais. 0 ecodesign prevê, sistêmica e antecipadamente, a redução de impactos ambientais durante todas as etapas do ciclo de vida do produto, ou seja, sugere redução do consumo de recursos (materiais e energéticos) desde a concepção até o descarte.

Essa necessidade de novos caminhos no âmbito projetual, aponta a responsabilidade do designer em conceber artefatos utilizando materiais e processos de baixo impacto ambiental; considerando o ciclo de vida inteiro do produto e, atuando de forma orientada para a sustentabilidade ambiental. O ciclo de vida compreende as etapas de pré-produção, produção, distribuição, uso e descarte e, em cada uma delas, os produtos acarretam impactos ambientais negativos (KAZAZIAN, 2005). Cardoso (2008) aponta o profissional de design como o agente capaz de projetar com uso mais eficiente dos recursos, maximizando o aproveitamento dos materiais consumidos.

É possível analisar o que alguns autores consideram importante para uma análise de ciclo de vida eficiente, já que como afirma Fuad-Luke (2002), cada um dos milhares de produtos criados para melhorar a qualidade de vida das pessoas tem alguma associação com impactos ambientais, sendo que alguns proporcionam pequenos impactos e outros podem consumir recursos finitos em grande quantidade. Papanek (1995, p. 35) considera que a avaliação do ciclo de vida do produto envolve, (...) desde a aquisição original das matérias-primas, passando pelo processo de transformação e montagem, a compra do produto acabado (que inclui também expedição, embalagem, publicidade e a publicação de manuais de instruções), o uso a recolha do produto 
após o uso e, finalmente, a reutilização ou reciclagem e tratamento final.

A estratégia do LCD, de Manzini e Vezzoli (2008) pode ser apresentada pela figura a seguir, que representa esquematicamente quais os principais pontos indicados por eles:

Figura 1: Estratégias de Life Cycle Design e fases do ciclo de vida.

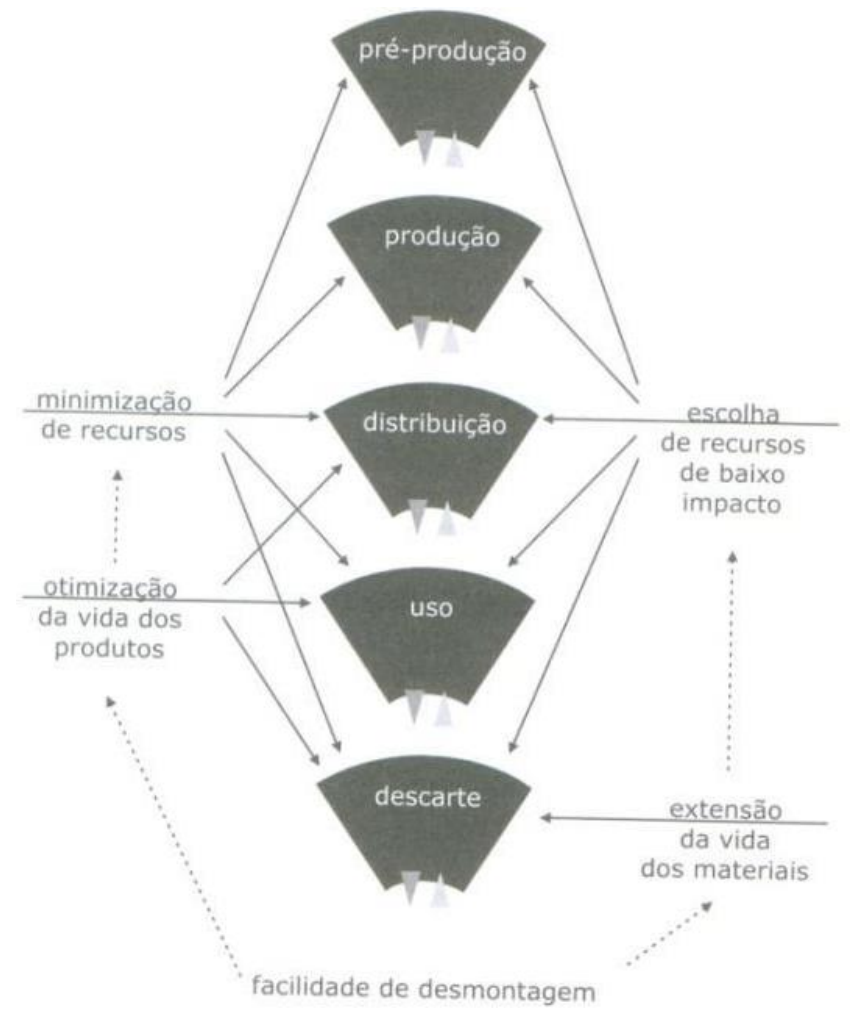

Fonte: Manzini e Vezzoli, 2008, p. 106.

Pensando na produção e na poluição, também é possível verificar o que Papanek (1995) indica considerando seis ciclos principais onde a criação e a fabricação de qualquer produto tanto em seu período de uso como em sua existência posterior - possui potencial de causar danos ao meio ambiente.

Primeiramente a escolha dos materiais, considerada crucial, pois o processo poderá acarretar em poluição atmosférica e destruição da camada de ozônio, desde a extração mineira devido ao consumo de combustíveis e gasto de recursos naturais que não podem ser renovados. Após, o foco é a fabricação do produto, onde se deve lembrar que os gases emitidos pelas chaminés das fábricas - promotores inclusive da chuva ácida - são poluentes atmosféricos. Nesta fase também poderão ser originados resíduos líquidos os quais poderão acabar por infiltrarem-se no solo e destruir terras aráveis ou, ainda, penetrar no sistema de abastecimento de água.

O terceiro ciclo trata da fase de embalagem do produto, nesta fase os materiais e a metodologia deverão ser considerados com enfoque em soluções ecológicas. Dessa maneira, também terá importância a embalagem utilizada no transporte, comércio e distribuição do produto. No quarto ciclo é feita uma análise do produto em si. A existência de várias versões do mesmo produto no mercado, levando-se em conta que para a fabricação dos mesmos são usadas matérias-primas insubstituíveis, podem constituir em uma profunda ameaça ecológica.

O ciclo seguinte trata do transporte de materiais e produtos, que também contribui para a poluição, consumindo combustíveis fósseis e criando a necessidade da existência de estradas, vias férreas, aeroportos e armazéns. No último ciclo observam-se as consequências negativas que os produtos podem ter depois de terminada sua utilidade, ou seja, quando muitas vezes é considerado lixo. 


\subsection{A empresa}

A empresa analisada foi fundada em 1993 e está situada na cidade de Caxias do Sul / RS. Há mais de 20 anos investe no desenvolvimento técnico e no design. Com muitos produtos já premiados em concursos de nível internacional, é possível perceber o resultado da dedicação da empresa em parceria com uma qualificada equipe de designers e técnicos.

A empresa é especializada na criação, desenvolvimento e fabricação de artigos para a decoração, organização e utilidades domésticas. No momento a empresa dispõe de três linhas básicas de produtos, sendo uma delas a linha denominada: Ecológica. A linha analisada apresenta produtos com material derivado do bagaço da cana-de-açúcar, que por suas características orgânicas é menos agressiva ao meio ambiente do que outras matérias primas existentes no mercado.

\subsection{Metodologia}

A pesquisa trata-se de um estudo de caso, pois segundo Rampazzo (2009) a investigação trata de um determinado indivíduo, família, grupo ou comunidade para examinar os aspectos variados de sua vida, amparando-se na análise qualitativa dos dados coletados. A metodologia utilizada é a coleta de dados, e os instrumentos utilizados são: questionário de perguntas abertas e análise documental (site da empresa).

A proposta é desenvolvida em três momentos distintos: o primeiro momento tratou de levantamento bibliográfico já apresentado que norteou e fundamentou a pesquisa, dando sustentação a proposta. Na sequência foi realizada a escolha do segmento a ser analisado e a busca pela empresa e seus produtos. Por fim, com a empresa escolhida, foram verificados os produtos oferecidos e a partir disto foi realizado contato com o responsável pela empresa a fim de dar continuidade a investigação, assim foi realizada a aplicação de questionário abordando quesitos relacionados ao processo produtivo, ao ciclo de vida e ao comprometimento da empresa com questões referentes à sustentabilidade. A seguir apresenta-se a análise destas questões.

\subsection{Análise e Discussão a partir da proposta de LCD}

Para a concepção de um produto que possa ser considerado sustentável é preciso observar - "Ciclo de Vida do Produto", para que seja verificado o quanto segue os requisitos de sustentabilidade em todas as etapas do seu ciclo de vida. Desta forma analisa-se seu possível impacto ambiental, a fim de reduzi-lo antes mesmo de colocá-lo no mercado, e isso é que o torna sustentável, por diminuir os impactos existentes na produção do mesmo.

As etapas que busca-se obter informações para análise são:

a) seleção de materiais;

b) processos de produção;

c) embalagem;

d) transporte;

e) ponto de venda;

f) uso;

g) pós-uso,

Para questionar e posteriormente analisar quais os pontos no ciclo de vida dos produtos da linha Ecológica são realmente diferentes dos produtos das outras linhas da mesma empresa, e qual o grau de sustentabilidade que esta linha carrega além do nome, foi preciso basear-se em bibliografia para a formulação das questões (MANZINI E VEZZOLI, 2008 E PAPANEK, 1995), possibilitando assim, que se realize perguntas que levam em conta todos os pontos considerados importantes no contexto. Deste modo serão apontados os objetivos que se busca investigar, 
definidos com base na bibliografia consultada, e os dados obtidos como resposta da empresa diante de tais questionamentos.

A primeira etapa evidencia os dados sobre a seleção de materiais, como: o buscar materiais não finitos, a(s) matéria-prima(s) utilizada(s), se este chega embalado na empresa, a ocorrência de desperdício de material, a possibilidade de reciclagem após o término do ciclo de vida da embalagem e preferencialmente, a escolha por um material que não precise ser misturado com outros materiais.

A empresa afirma trabalhar somente com o material chamado Plastwood Composto de Cana. Este material é adquirido da empresa terceirizada, que é uma subdivisão da empresa especializada, com sede em Campo Bom, no estado do Rio Grande do Sul. Este material chega em grânulos na forma sólida. Este material é embalado em sacos plásticos, proveniente da Implac de Santa Catarina. Não há indicadores do fabricante da embalagem. Todo o material que chega é processado por completo, pois o mesmo tem prazo de validade. Caso ocorra de ter uma pequena sobra e o mesmo não puder ser processado e tiver com o prazo de validade vencido, o mesmo terá que ser descartado. A distância é de $931 \mathrm{Km}$ pela BR 116, e o material sai da cidade de TatuiSP. O material é transportado por meio rodoviário (caminhões). Como é feito compras fracionadas, a mesma deixa espaço na carroceria Toda a matéria prima é proveniente do bagaço da cana de açúcar que sobra das refinarias, e as mesmas são reprocessadas e é adicionado polímero para formar o composto. Quanto ao gasto energético, não saberia quanto é gasto, mas há o gasto energético das refinarias, bem como, o óleo diesel gasto pelos tratores que fazem a extração. É uma matéria prima secundária. O reprocessamento ocorre em outra indústria na empresa terceirizada, não é feita no local da extração. Ela é transportada via rodoviário da refinaria até a mesma. Somente depois de ser reprocessada pela empresa terceirizada, que o composto pode ser transportado para a empresa.

Após os questionamentos sobre a etapa de seleção de materiais, a seguir são observados os processos de produção dos produtos da empresa em geral e especialmente dos produtos da linha analisada. Sendo assim, busca-se informações que visam verificar se a empresa tem atenção desde os métodos de fabricação menos agressivos, observando o consumo energético das máquinas, os possíveis resíduos - sejam eles, líquidos, sólidos ou gasosos - eliminados durante os processos e, no caso de ser inevitável a eliminação de resíduos, procura-se por uma reutilização em algum outro sistema, destinando-os a outras máquinas no caso dos líquidos; colocando filtros no caso dos gasosos e coletando corretamente os sólidos para um destino que não sejam despejados em rios, matas, solos aráveis, sistemas de abastecimento de água, etc.

Em resposta a empresa diz utilizar apenas um processo, a injeção. A quantidade de máquinas é variável, depende da programação e da quantidade de componentes utilizados na montagem do produto O maquinário adquirido após 2005, mais modernos, já estão sendo fabricados com sistema que reduz o consumo de energia elétrica. Também dispõe de geradores para ajudar na redução no consumo energético. A empresa preocupa-se em dar o destino correto a todos os materiais com base na legislação vigente. Todo o processo é igual para ambas as linhas de produtos. O produto é embalado tão logo a sua injeção, não sendo necessário seu transporte até outro local. Recebe-se a matéria-prima pronta para consumo, a composição química e/ou alguma junção que seja utilizada, esse é realizada pelo próprio fornecedor.

A etapa seguinte é referente ao embalo dos produtos. Sendo importante considerar todas as embalagens utilizadas nas diferentes etapas da vida do produto, o que engloba a proteção do produto nas próximas etapas de seu ciclo de vida. No caso do produto ser a própria embalagem, não há a necessidade de embalar, no entanto, deve-se pensar em formas de empilhar, encaixar, compactar para facilitar o manuseio necessário nas etapas seguintes. Faz-se necessário analisar 
este quesito nas diversas etapas do ciclo de vida do produto para verificar a necessidade de utilização de uma ou mais embalagens, de acordo com suas funções e com as reais necessidades do produto.

O retorno é de que as embalagens utilizadas são saco plástico e caixa de papelão corrugado, adquiridas de terceiros. Essas embalagens são as mesmas utilizadas para os produtos das outras linhas. As embalagens são produzidas por outras empresas e transportadas até aqui. Estes terceiros dispõem de cuidados sustentáveis, porque essa também é uma preocupação da empresa com os fornecedores. É necessária para a proteção da peça para o transporte, evitando as avarias.

Verificados os tópicos referentes ao processo de embalo e às embalagens utilizadas nos produtos da empresa, a próxima etapa apresenta as observações relacionadas ao transporte, que considera tópicos como otimização de espaço no meio de transporte escolhido para que o número de veículos seja o menor possível, na busca pelo uso de biocombustíveis ao invés de combustíveis fósseis e ainda no incentivo do varejo para a compra de produtores locais, que diminui a distância necessária a ser percorrida e auxilia o crescimento econômico regional. Obtendo como resposta da empresa que a mesma pensa e analisa a logística de todo o processo, visando sempre reduzir tempo e custos. Rodoviário é o principal, mas utiliza-se também marítimo e aéreo.

No ciclo de vida, deve-se considerar também o ponto de venda dos produtos de linha, a necessidade de diferenciais e o formato de venda adotado pela empresa. Na empresa analisada, os produtos são expostos em pontos de venda normais, ou seja, em gôndolas dos próprios estabelecimentos comerciais. Devido a essa escolha, gera-se uma movimentação de vendedores para que ocorra armazenamento das gôndolas, depósitos ou até mesmo tele entregas.

A questão de uso, algumas vezes esquecida propositalmente pelas empresas, por envolver o consumidor de forma mais direta que a própria empresa, também deve ser levada em consideração, visto que é possível prever intervenções ainda na fase de desenvolvimento do produto para esta etapa. De forma geral, a forma de uso de produtos da linha Ecológica e produtos das demais linhas da empresa não diferem. Características de durabilidade, resistência e outros quesitos técnicos não sofrem alterações da concepção de uma linha para a outra. As funções do produto também não sofrem alteração ao se considerar a linha Ecológica. São produtos que não carecem de consumo energético ou absorção de recursos para uso, além de não gerar resíduos - somente após finalizar sua vida útil. Destaca-se que o formato dos produtos da linha Ecológica não são diferenciados, porém algumas características são ressaltadas, como um cuidado maior na exposição nos pontos de venda com apelo voltado a fabricação que faz uso de fibras naturais de cana-de-açúcar e/ou madeira.

E, por fim, após análise do uso do produto, são consideradas as questões sobre as possibilidades de pós uso. A etapa de pós uso, algumas vezes, é ignorada pelas empresas, que buscam fugir da responsabilidade sobre seus produtos por considerarem que o consumidor deveria pensar na forma de descartá-los. Porém, sabe-se que são difundidos meios de envolvimento das empresas com etapa, visando o retorno, reaproveitamento e até mesmo reparo de seus produtos.

$\mathrm{Na}$ busca de compreender como a empresa em questão trabalha esta última etapa, questionou-se se o produto pode receber uma nova função do consumidor, voltar ao ciclo produtivo ou até mesmo ser reciclado. Em resposta a empresa salientou que o produto é reciclável, porém, não retorna para a empresa, tornando-se uma tarefa de responsabilidade do usuário. Também não há um sistema para recolher os produtos após o uso. $O$ fato de ser um produto com matéria-prima diferenciada de outras linhas, seu sistema de coleta e descarte não são diferenciados. Com a possibilidade da reciclagem, após a moagem do material, pode ser reutilizado por meio de processo de injeção de outras peças ou componentes. Trata-se do processo de reciclagem tradicional do plástico. 
Com os dados apresentados é possível analisar os diferenciais que a linha de produtos ecológicos traz consigo além do próprio nome. Buscou-se fazer questionamentos que demonstrem, em cada etapa do ciclo de vida dos produtos, quais pontos de diferenciação existem ou deveriam existir entre a linha em questão - com apelo à sustentabilidade, e as outras linhas de produtos ofertadas pela empresa - sem este apelo.

As respostas da empresa mostram a preocupação que a mesma tem com a sustentabilidade e quais atitudes são tomadas para que seus produtos se destaquem no mercado neste sentido. Alguns pontos revelados demonstram o empenho da empresa em seguir as normas determinadas por lei referentes à problemática em questão, outras respostas mostram preocupações relacionadas, por exemplo, aos materiais, processos e visão de pós uso.

\section{CONCLUSÃO}

A relação do design com a sustentabilidade fica explícita uma vez que o primeiro implica na fabricação de artefatos e que estes, em seu ciclo de vida, geram impactos no meio ambiente. As empresas que agem em busca de uma produção sustentável, e não apenas visando o lucro, estimulam e conscientizam o consumidor que passa a ter novas alternativas, e ajudam na preservação ambiental.

A abordagem de ecodesign é uma estratégia importante, pois considera o ciclo de vida dos produtos, o que compreende uma visão sistêmica e integrada. Portanto o processo produtivo e criativo não deve estar focado apenas no lucro e no estímulo inicial ao consumo, mas em uma proposta que busca a adoção de novos valores da sociedade.

Desta forma, o designer deve atuar no desenvolvimento de projetos considerando essa ferramenta para projetar. Aplicar a sustentabilidade na questão projetual, pode ser feito por meio da inclusão do hábito de prever, durante o desenvolvimento dos produtos, nas etapas de geração de alternativas projetuais, quais as coordenadas e linhas guias que podem promover uma relação desejável entre o projeto, a produção e o fim de vida destes produtos, ou seja, todo seu ciclo de vida.

No caso da empresa analisada, percebe-se que com os dados apresentados nos quadros, o que a linha Ecológica da empresa tem de diferencial, se comparada às outras linhas, é em especial a matéria prima utilizada, pois nos outros pontos não foram observadas diferenças tão significativas que possam destacar o produto como mais sustentável. Contudo, considera-se que a escolha de um material diferenciado faz com que outros benefícios possam ser percebidos em mais etapas do ciclo de vida do produto.

Este é um caso apenas, mas que pode provocar uma reflexão sobre o que se consome, quando se consome e de quem se compra quando consome, e, principalmente qual a responsabilidade do designer neste processo. A análise do ciclo de vida, a partir da ótica do design, serve para que ainda durante os projetos, seja possível atuar realizando intervenções pontuais, em busca de minimização de impactos e escolhas mais conscientes, além da visão sistêmica inerente ao designer diante do compromisso com a sustentabilidade ao desenvolver produtos.

É evidente a importância de uma análise mais detalhada, de cada etapa e de cada diferença entre as linhas da empresa para um possível "cálculo do grau de sustentabilidade" da linha de produtos que carrega o termo 'Ecológica' no nome, porém devido à maior complexibilidade, não caberia ser feita em um artigo somente.

A necessidade de uma análise mais aprofundada é considerada, pois pode contribuir inclusive para revelar outros cuidados tomados pela empresa no dia-a-dia. Visto que é possível que algumas atitudes não tenham sido reveladas nas respostas do questionário, por fazerem parte 
dos processos em geral e rotineiros da empresa. Por isso, é possível que mais atitudes positivas com relação à empresa e ao tema da sustentabilidade ocorram, mas o respondente do questionário pode não ter percebido possíveis implicações e suas relações com o tema.

Apesar da visível e crescente preocupação das empresas para com a sustentabilidade, e até mesmo referindo-se ao caso apresentado neste artigo, pode-se considerar uma lástima que nos dias de hoje seja preciso criar linhas de produtos com maior preocupação ambiental. Afinal, a consciência acerca do problema deveria fazer com que todos os produtos tenham esses cuidados intrínsecos à fase de projeto, e assim, o consumo da população seria voltado à sustentabilidade de forma geral, independente de qual produto a pessoa esteja interessada em consumir.

\section{REFERÊNCIAS}

CARDOSO, R. Uma introdução à história do design. 3. ed. São Paulo: E. Blucher, 2008. 273 p.

DE MORAES, D. Metaprojeto: o design do design. São Paulo: Blucher, 2010.

FUAD-LUKE, A. Manual de Diseño Ecológico. Londres: Editorial Cartago S.L., Thames \& Hudson Ltda., 2002.

KAZAZIAN, T. (org.) Design e desenvolvimento sustentável Haverá a idade das coisas leves. Trad. Eric Roland Rene Heneault. - São Paulo: Editora Senac São Paulo, 2005.

LAWSON, B. How Designers Think: The Design Process Demystified. Londres: Routledge, 2006.

MANZINI, E.; VEZZOLI , C. O desenvolvimento de produtos sustentáveis. São Paulo: Editora da Universidade de São Paulo, 2008.

MANZINI, E. Design para a inovação social e sustentabilidade: comunidades criativas organizações colaborativas e novas redes projetuais. Trad. Carla Cipolla. (Cadernos do Grupo de Altos Estudos; v. 1) Rio de Janeiro: E-papers, 2008.

MARGOLIN, V.; MARGOLIN, S. Um "modelo social” de design: questões de prática e pesquisa. Revista Design em Foco. Salvador: Universidade do Estado da Bahia, Julho-Dezembro/2004.

PAPANEK, V. Arquitectura e Design. Ecologia e Ética. Lisboa: Edições 70, 1995.

RAMPAZZO, L. Metodologia Científica. 4ạed. São Paulo: Edições Loyola, 2009.146p.

VEZZOLI, C. Design de sistemas para a sustentabilidade: teoria, métodos e ferramentas para o design sustentável de "sistemas de satisfação". Salvador: EDUFBA, 2010. 